\title{
ANÁLISE DE HISTÓRIAS PRODUZIDAS A PARTIR DA OBSERVAÇÃO DA ILUSTRAÇÃO SEQUENCIAL “INFAUSTAS AVENTURAS DO SENHOR PANCRACIO”
}

Design da informação, ilustração sequencial, memória gráfica
Information design, sequential illustration, graphic memory
Este artigo apresenta os resultados de um estudo de campo de natureza semiestruturada e qualitativa, no qual foi utilizada uma ilustração sequencial denominada "Infaustas Aventuras do Senhor Pancracio" originaria de uma revista ilustrada do final do século XIX intitulada "O Diabo a Quatro". A pesquisa consistiu na realização de 10 de entrevistas com sujeitos, de idades entre 22 a 39 anos, todos com formação superior; cada participante criou histórias a partir da observação desta ilustração. Posteriormente as narrativas expressas pelos participantes foram analisadas, com o objetivo de verificar as impressões que emergiram pelo olhar contemporâneo a partir da observação desta sequência do século XIX.

This article presents the results of a field research with a semi-structured, qualitative approach, in which a sequential illustration was used, called "Infaustas Aventuras do Senhor Pancracio", which was originally published in an illustrated magazine during the late nineteenth century entitled "O Diabo a Quatro" (The Devil on All Fours). This research consisted of 10 interviews with individuals aged between 22 and 39 years, all with a university degree. Each participant created stories from observing this illustration. At a later date, the narratives expressed by the participants were analyzed in order to verify the impressions that emerged from a contemporary viewpoint by observing the sequence from the nineteenth century.

\section{INTRODUÇÃO}

Em meados do século XIX em Pernambuco a cultura dos impressos se disseminava e ganhava espaço dentro do cotidiano da sociedade do período. Aos poucos os avanços tecnológicos para a reprodução de imagens, principalmente a partir da técnica da litografia, começaram a ser cada vez mais utilizados para estampar diversas publicações do período, surgiram assim, as chamadas Revistas Ilustradas. 
A partir da década de 1860 cresce a quantidade de periódicos dedicados à sátira política e à crônica de costumes. Eles constituem a face mais conhecida da memória gráfica brasileira do século XIX. Em sua maioria, as edições são formadas por uma única folha com duas dobras alternadas, gerando um caderno de oito páginas (...) a ilustração domina as capas, sendo os títulos das publicações invariavelmente tratados como desenhos, numa fusão entre texto e imagem. (Melo e Ramos, 2011: 47)

Foram inúmeras as publicações deste gênero em Pernambuco, entretanto segundo Cavalcanti (1996) "A mais importante revista ilustrada deste final do século XIX, porém, vem a ser O Diabo a Quatro - Revista infernal, trazendo ilustrações e charges de José Neves e Antônio Vera Cruz".

“O Diabo a Quatro - Revista Infernal”, circulou semanalmente no Recife entre 11 de julho de 1875 a 15 de maio de 1879, possuía cunho humorístico e crítico onde os seus desenhos e textos que apoiavam a política liberal republicana, satirizavam o Governo Imperial, e ainda faziam crônicas de costumes e hábitos do período. Uma das definições de Jacobson para o design da informação, pode ser relacionada ao trabalho executado pelos artistas gráficos de O Diabo a Quatro:

Minha crença é que há uma prática de design exclusivo que pode ser identificado como o design de informação. Sua finalidade é a disposição sistemática e utilização de veículos de comunicação, canais e símbolos para aumentar a compreensão dos participantes em uma conversa ou discurso específico. (JACOBSON, 2000: 8-9)

Além de serem propagadoras de informações, diversas ilustrações deste periódico, ainda apresentam discursos e personagens que lhes conferem a característica sequencial, para este artigo foi selecionada uma ilustração de página central intitulada "Infaustas Aventuras do Sr. Pancracio", que apresenta uma sequência de fatos em formato de historieta em quadrinhos.

No primeiro momento do desenvolvimento foi realizada uma análise da ilustração, alguns quadros são descritos, ressaltando sua narrativa, personagens, ações, significados e destacando elementos que são característicos de artefatos sequenciais. Apresentaremos em seguida o experimento realizado com a mesma, durante a fase do estudo de campo, que tinha por objetivo verificar as impressões que surgiram segundo a observação desta sequência. Para tal foram realizadas entrevistas nas quais ocorreram a criação de narrativas a partir da apreciação da ilustração selecionada. Posteriormente demonstraremos os resultados que foram constatados a partir da minuciosa análise dos discursos dos participantes. 


\section{DESENVOLVIMENTO}

\subsection{Elementos Gráficos e Sequenciais nas Infaustas Aventuras do Sr. Pancracio}

Entre 1875 e 1879, circularam 195 números de "O Diabo a Quatro", mas é na publicação do número 17 de 31 de outubro de 1875, onde encontramos a ilustração selecionada para o estudo do presente artigo, ocupando as páginas centrais com uma divertida historieta em quadrinhos de autoria de Antônio Vera Cruz, composta de 20 quadros com o título: "Infaustas Aventuras do Sr. Pancracio" (Figura 1), onde é contada a visita do Sr. Pancracio um senhor de engenho ao Recife para negociar a venda de sua produção. Criando algumas situações o ilustrador demonstrou a estranheza, causada entre alguns membros da sociedade tradicional, com as inovações tecnológicas e culturais que tomavam conta do Recife.

Os 20 quadros da ilustração são acompanhados de texto-legenda, uma das características destacadas por alguns autores como Spinillo (2000), a qual sugere que o texto relacionado a imagem é importante para um melhor entendimento do conteúdo gráfico, neste caso em análise o texto-legenda ressalta detalhes importantes dos quadros auxiliando no entendimento da sequência dos fatos apresentados. A legenda juntamente com a forma como estão alinhados os quadros também contribui para a definição da sequência de leitura da ilustração, horizontal, da esquerda para a direita.

Figura 1 O Diabo a Quatro - 31.10.1875, $\mathrm{n}^{\mathrm{o}} 17$.

Fonte: Elaborado pelos autores, com base na pesquisa realizada no acervo da Biblioteca Pública de Pernambuco (BPE).

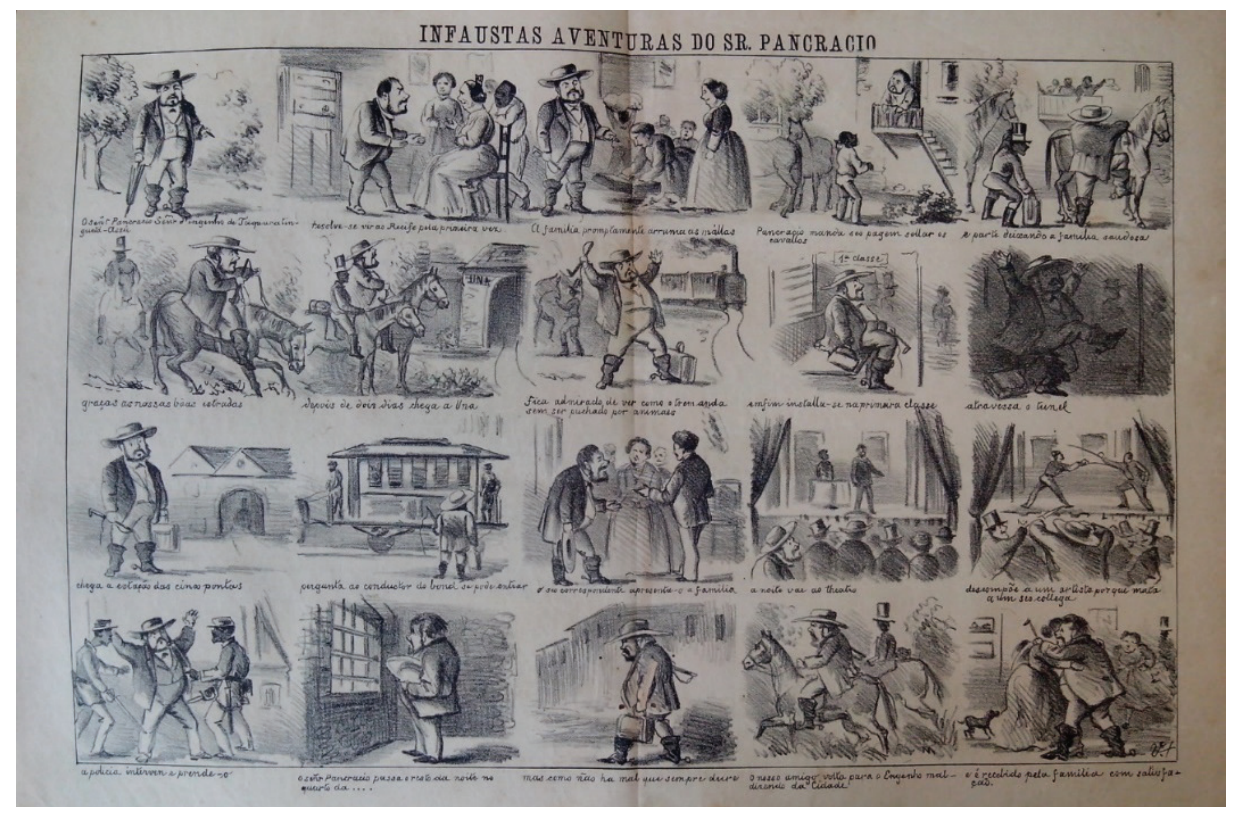


1 Na primeira metade do século XIX, a cromolitografia (método da litografia no qual os desenhos passaram a ser impressos em cores) já era utilizada na Europa e nos Estados Unidos, entretanto Barreto Campello (2011: 14) ressalta, "no primeiro quartel do século XX, a litografia comercial recifense atinge um razoável amadurecimento (...) os trabalhos da Fábrica Lafayette de cigarros em cromolitografia são um bom exemplo". Assim apesar de existir no mesmo período de circulação de O Diabo a Quatro a técnica da cromolitografia ainda não era amplamente utilizada nas revistas ilustradas no Brasil.
Contidos em um grande retângulo, estão os 20 quadros menores delimitados por pequenos espaços existentes entre os mesmos que Spinillo (2000), destaca como elementos de separação visual. Outro autor, Peeters (1991) além de quadro ou quadrinho, utiliza o termo box, ressaltando que são elementos que constituem os artefatos em sequência, pois definem o espaço necessário para a representação de eventos ou ações comunicativas nas sequencias. Marcando momentos na continuidade da narração.

Os boxes podem ser visíveis ou invisíveis. Cada porção da narração ocupa um lugar no espaço gráfico e deduzimos as linhas separando uma da outra, mesmo quando o box e as linhas de divisão não são desenhadas. Como podemos observar na ilustração do Sr. Pancracio.

A ausência de cor na ilustração ainda é reflexo da técnica de impressão utilizada, a litografia, que apesar de ter sido um grande avanço tecnológico para a época ainda possuía ${ }^{1}$ algumas limitações. Litografia que significa "desenhar na pedra". Foi criada em 1796 por Aloys Senefelder (1771-1834), sobre a mesma Meggs (2009: 198) define:
A litografia se baseia no princípio químico simples que óleo e água não se misturam. A imagem é desenhada numa superfície plana de pedra com crayon, caneta ou lápis de base oleosa, que repele a água. Em seguida, uma tinta também de base oleosa é passada com um rolo sobre a pedra, aderindo a imagem, mas não as áreas molhadas. Uma folha de papel é colocada sobre a imagem e utiliza-se uma prensa para transferir a imagem entintada para o papel.

A seguir apresentaremos alguns quadros da ilustração, destacando a ligação com alguns dos elementos ressaltados anteriormente, o contexto histórico, cultural e social do período e os significados contidos na representação da história.

\subsection{O Sr. Pancracio e a Modernidade no Recife}

No início da década de 70 do século XIX, já faziam 43 anos que o Recife havia sido elevado a condição de capital de Pernambuco. O antigo povoado onde outrora ficava o porto comercial de Olinda, tornara-se uma cidade bem estruturada, que agora abrigava os principais órgãos incumbidos pela economia e administração da Província. Formado pelos bairros: Santo Antônio, São José e Boa Vista, que mantinham contato com bairros menores, o Recife crescia tentando se adequar a uma nova concepção de sociedade moderna e civilizada que evoluiria com a chegada do século XX.

Entre as modificações que ocorriam a impressa jornalística se tornava dinâmica e produtiva e os editores de O Diabo a Quatro encontravam-se de certa forma antenados com as transformações da cidade. "As Infaustas aventuras do Sr. Pancracio" enfatizam a questão 
da modernização e os conflitos de valores de uma modernidade urbana que contrastava com a sociedade conservadora do período. O personagem principal (Figura 2), aparece vestindo roupas que fazem referência a um coronel ou homem de prestigio e poder da época, no canto inferior do quadro esta o texto-legenda que diz: " $O$ Señr Pancracio Señr d engenho de Taquaratinguetá-Assú” define assim, um típico dono de engenho que fazia parte da elite conservadora e patriarcal.

Figura 2 O Diabo a Quatro - 31.10.1875, $\mathrm{n}^{\circ} 17$.

Fonte: Elaborado pelos autores, com base na pesquisa realizada no acervo da BPE.

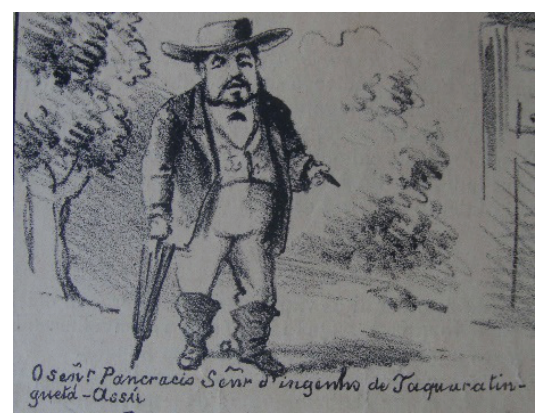

É valido destacar que entre todos os quadros da ilustração mesmo sem a presença de linhas ou traços que delimitem a área de ação de cada um, existe um espaço que auxilia o observador nesta distinção, porém entre os quadros 2 e 3 (Figura 3) esse espaço parece não ter a mesma ênfase dos demais, chegando quase a parecer um único quadro. A presença do texto-legenda ajuda a compreensão de que se trata de dois momentos, apesar de ambos possuírem o mesmo cenário o da Casa-Grande do engenho. Lê-se no primeiro: "resolve-se vir ao Recife pela primeira vez", enfatizando a viagem que será mostrada. E a legenda seguinte diz: "a família promptamente arruma suas mállas", compreendemos assim que os novos personagens que tem uma função secundária no enredo da história constituem a família de Pancracio, algumas mulheres bem vestidas e um negro descalço, que representa a presença da escravidão, são personagens de uma típica família Patriarcal. 
Figura 3 O Diabo a Quatro - 31.10.1875, $\mathrm{n}^{\circ} 17$.

Fonte: Elaborado pelos autores, com base na pesquisa realizada no acervo da BPE.

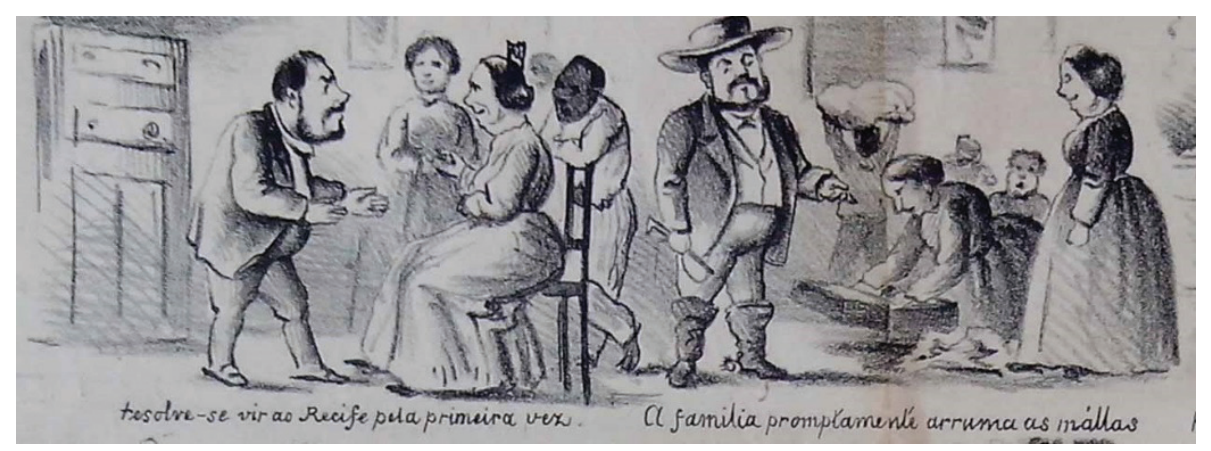

Após despedir-se da família, o Senhor Pancracio parte a cavalo acompanhado do seu escravo em direção ao local onde pretende tomar o transporte para a capital. No oitavo quadro (Figura 4), aparece assustado com o primeiro elemento que representa modernidade. $\mathrm{O}$ texto-legenda ressalta: "fica admirado de ver como o trem anda sem ser puxado por animais".

Figura 4 O Diabo a Quatro - 31.10.1875, $\mathrm{n}^{\mathrm{o}} 17$.

Fonte: Elaborado pelos autores, com base na pesquisa realizada no acervo da BPE.

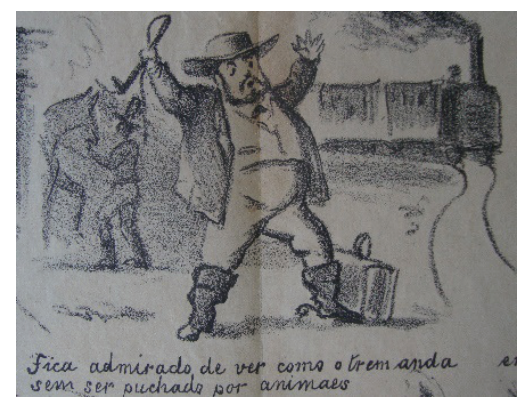

Toma o trem, no nono e décimo quadros (Figura 5) lê-se "enfim installa-se na primeira classe", enfatizando mais uma vez seu nível social. No quadro 10 ele surge novamente espantado e além dos braços até uma perna também está levantada, o quadro escuro parece meio confuso, a legenda revela o motivo da escuridão: "Atravessa o túnel". O túnel, outro elemento da modernidade, simboliza uma espécie de passagem entre dois mundos: o rural e o urbano da modernidade da Capital. 
Oliveira Í. S. C. S., Silva F. B., Miranda E. R., Coutinho S. G. \& Leite H. L. A. | Análise de histórias produzidas a partir da observação da ilustração sequencial "infaustas aventuras do Senhor Pancracio"

Figura 5 O Diabo a Quatro - 31.10.1875, $\mathrm{n}^{\circ} 17$.

Fonte: Elaborado pelos autores, com base na pesquisa realizada no acervo da BPE.

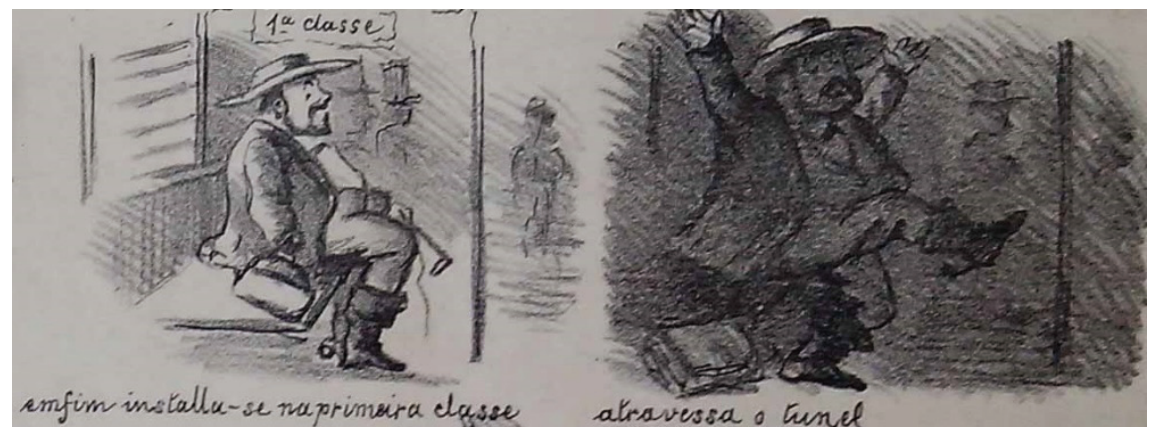

No décimo segundo quadro (Figura 6), ao chegar na Capital, um outro meio de transporte parece lhe deixar intrigado, para os moradores da cidade era comum pegar o bonde ${ }^{2}$ nas ruas do Recife, mas o senhor Pancracio, segundo o texto: "pergunta ao condutor do bond se pode entrar". Curioso notar que mesmo sendo ainda puxado por animais este meio de transporte pareceu confundir o personagem.

Figura 6 O Diabo a Quatro - 31.10.1875, $\mathrm{n}^{\circ} 17$.

Fonte: Elaborado pelos autores, com base na pesquisa realizada no acervo da BPE.

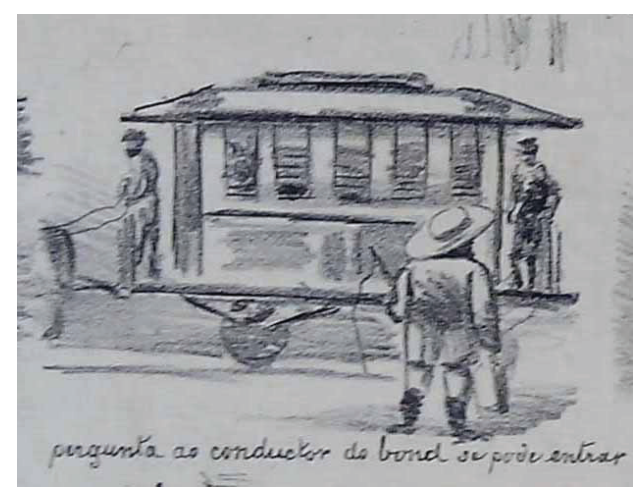

2 O bonde de burros na sua velocidade incomparável aos seus sucessores modernos. Os bondes eram calmos, vagarosos e simples. Inimigos da agitação. (REZENDE, 1997: 59 $-60)$.
No quadro seguinte (Figura 7) ele surge na companhia de um homem e uma mulher, parece estar em uma residência, visualizando apenas a ilustração não fica claro de quem se tratam esses personagens secundários, mas ao ler o texto legenda: "o seo correspondente apresenta-o a família”, segundo Eisenberg (1977) os donos de engenho levantavam capital a partir de uma fonte, um agente comercial no Recife conhecido como correspondente ou comissário. Fica clara agora a motivação da viagem do Senhor Pancracio ao Recife, foi fazer negócios. 
Oliveira Í. S. C. S., Silva F. B., Miranda E. R., Coutinho S. G. \& Leite H. L. A. | Análise de histórias produzidas a partir da observação da ilustração sequencial "infaustas aventuras do Senhor Pancracio"

Figura 7 O Diabo a Quatro - 31.10.1875, $\mathrm{n}^{\circ} 17$.

Fonte: Elaborado pelos autores, com base na pesquisa realizada no acervo da BPE.

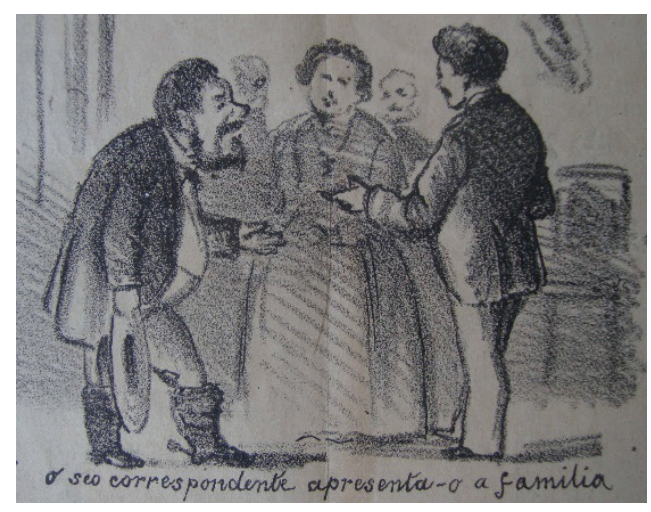

Além de realizar negócios, na sequência vai ao teatro, onde se envolve em uma confusão nos quadros 15 e 16 (Figuras 8 e 9) Pancracio assiste à apresentação, porém em uma cena onde era representado um conflito, uma espécie de duelo de espadas, e um dos atores é atingido em luta, ele decide ajudá-lo e, de faca em punho, tenta subir no palco para salvá-lo. No texto lia-se: "descompõe a um artista porque mata a um seo collega". Por não ter compreendido a peça, e ter causado tumulto no quadro seguinte ele aparece de mãos para o alto com expressão de espanto, sendo abordado por dois policiais de espada em punho, a legenda ressalta: "a policia intervem e prende-o".

Figura 8 e 9 O Diabo a Quatro - 31.1.1875, n $^{0} 17$.

Fonte: Elaborado pelos autores, com base na pesquisa realizada no acervo da BPE.
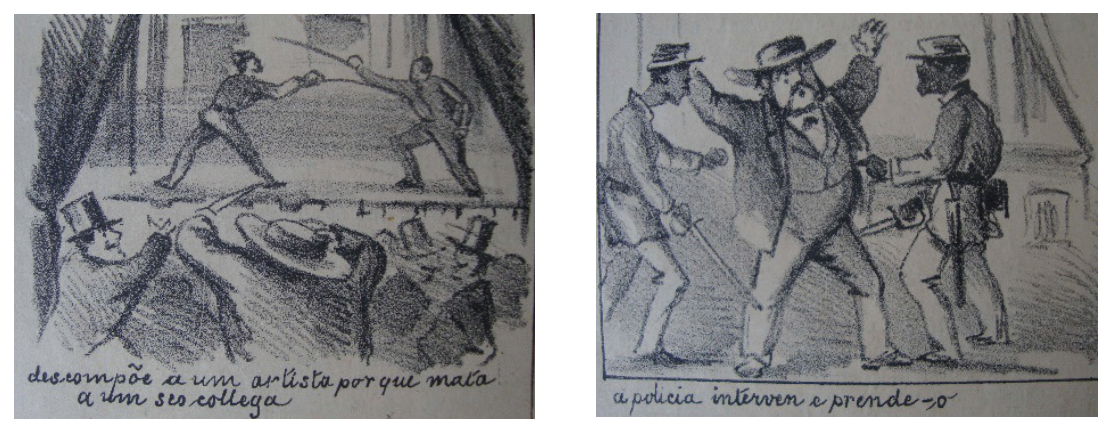

É válido ressaltar que nesses quadros apresentados até o momento Pancracio foi desenhado acompanhando a sequência de leitura (da esquerda para a direita). Entretanto nos últimos quatro quadros da sequência, o ilustrador inverteu o sentido, desenhando o personagem voltado da direita para a esquerda, talvez porque após ter sido surpreendido por tantos elementos que lhe causaram desconforto, Pancracio decidiu fazer o caminho de volta. Esta inversão do sentido 
do personagem é percebida ainda com o mesmo na cidade nos quadros 17 e 18 (Figura 10). Primeiramente com ele preso segurando o chapéu, onde a legenda diz: "o señr Pancracio passa o resto da noite no quarto da ...", e na sequência, já se encontra solto, a legenda complementa: "mas como não ha mal que sempre dure" confirmando sua libertação.

Figura 10 O Diabo a Quatro - 31.1.1875, $\mathrm{n}^{\circ} 17$.

Fonte: Elaborado pelos autores, com base na pesquisa realizada no acervo da BPE.

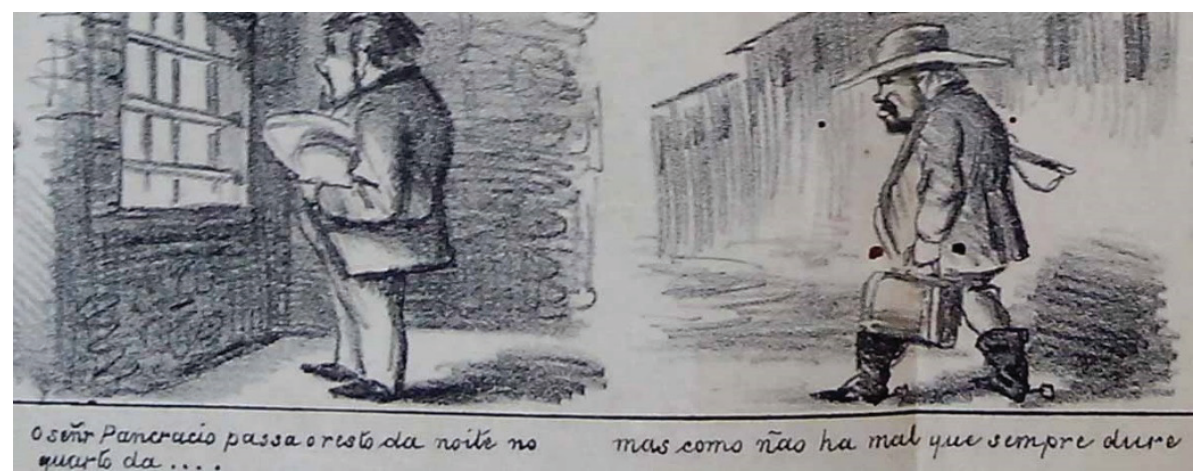

Os quadros finais (Figura 11) apresentam o Senhor Pancracio em outro cenário. Está novamente cercado por vegetação em um meio rural. No último quadro, "é recebido pela família com satisfação", no canto inferior encontra-se a assinatura do ilustrador Antônio de Vera Cruz, um V. seguido do sinal da (+).

Figura 11 O Diabo a Quatro - 31.1.1875, $\mathrm{n}^{\circ} 17$.

Fonte: Elaborado pelos autores, com base na pesquisa realizada no acervo da BPE.

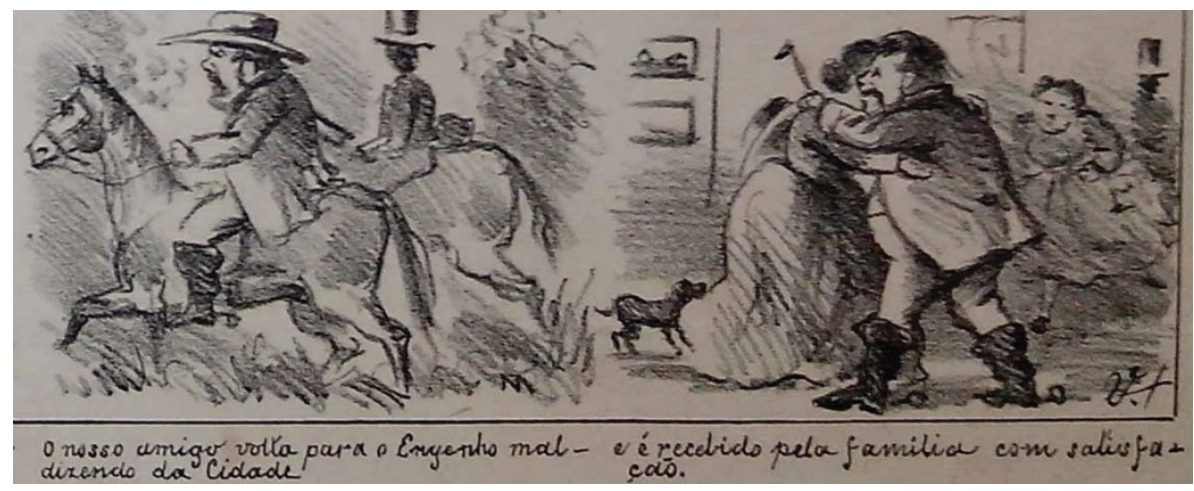

Os quadros formam uma sequência que apresentam o Senhor Pancracio em situações cômicas onde age de forma grosseira, demonstrando que os habitantes do meio rural possuíam hábitos cotidianos divergentes daqueles ocorridos no meio urbano. O trem, o túnel, o bonde e a peça teatral representam algumas transformações tecnológicas e culturais que tomavam a Capital, desde meados do 
século XIX. Por constituir uma sequência rica em detalhes esta ilustração foi escolhida para o experimento que descreveremos a seguir.

\subsection{Etapas do Estudo de Campo}

A pesquisa foi realizada a partir de 10 de entrevistas com sujeitos entre 22 a 39 anos, todos com formação superior de diversas áreas (Humanas, Exatas e Saúde).

Todas entrevistas foram gravadas com imagem e som e posteriormente transcritas resultando na elaboração de fichas para a análise do discurso de cada participante. Segue abaixo (Figura 12) o modelo de ficha elaborada a partir da ilustração, composta por duas partes: "Sequência Original", que contém os quadros da ilustração com numeração e setas que definem a ordem de leitura e no final desta etapa existe uma justificativa para a ordem de leitura; a segunda parte, "Discurso Original", contém a transcrição das legendas que acompanham a ilustração numeradas de acordo com cada quadro a que correspondem. Em cada frase das legendas foram destacados alguns elementos da narrativa: Personagem Principal, Personagens Secundários, Ações, Objetos e Artefatos e Cenários.

Figura 12 Ficha base para análise das narrativas dos participantes.

Fonte: Elaborado pelos autores, com base na pesquisa realizada.

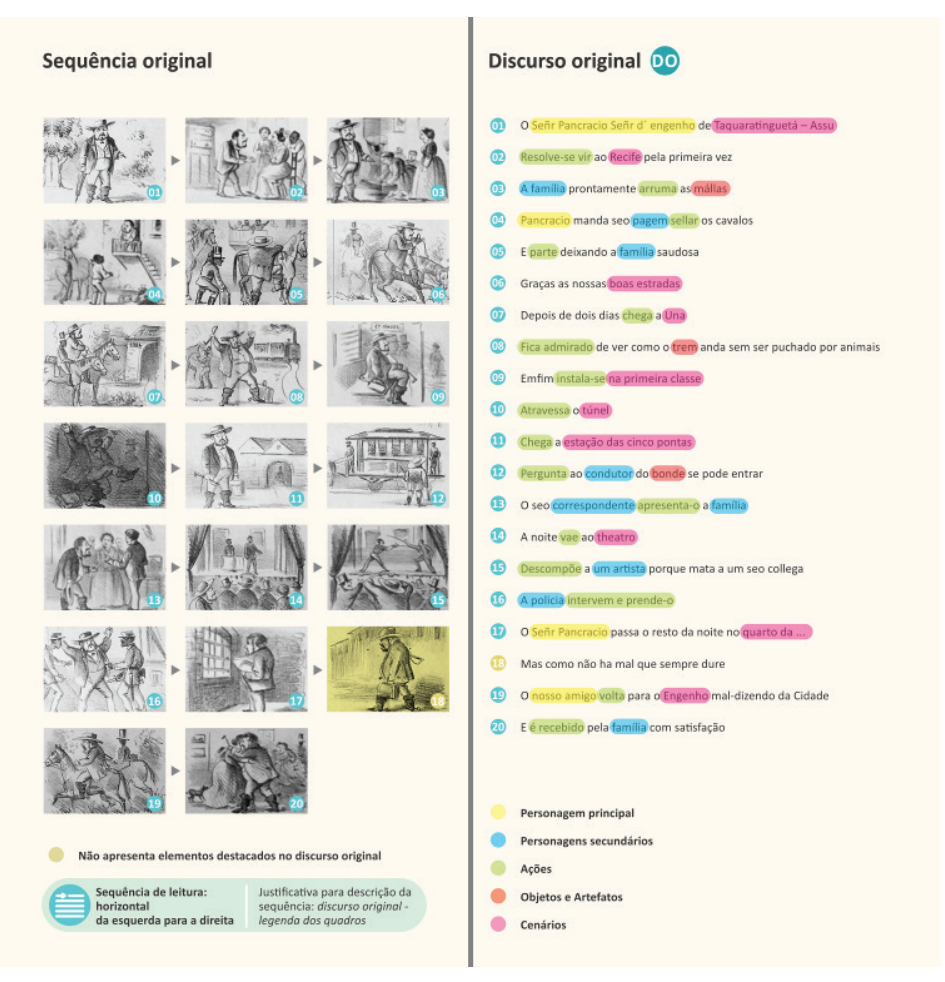


Os participantes receberam a ilustração impressa no tamanho A3, porém sem a presença do texto-legenda, pois o objetivo principal era que os participantes criassem uma narração a partir da sequência de ilustrações do Senhor Pancracio. Como foi constatado durante a análise da mesma, que o texto-legenda além de fornecer detalhes da narrativa, ainda apontava o sentido de leitura da sequência, e estes são elementos que também foram observados durante as entrevistas, foi decidido retirar qualquer intervenção da legenda, para poder deixar o máximo de liberdade nas escolhas e decisões dos entrevistados.

As entrevistas possuíram o seguinte protocolo de solicitação aos participantes: 1 - Criar uma história a partir desta ilustração; 2 - Como ocorreu a escolha do sentido de leitura da sequência?; 3 Esta ilustração é recente ou antiga?; 4 - Que elementos da ilustração levaram a esta conclusão?

Após as etapas anteriores foi fornecida a ilustração com o texto-legenda para que os participantes comparassem sua versão da história/narração com a original, e para finalizar foram feitos os seguintes questionamentos: 1 - Se ocorreu o pulo de algum dos quadros, questionar o motivo?; 2 - Se a legenda foi primordial para o entendimento da história?

As fichas de análise possuem algumas modificações nos títulos a primeira parte passou a ser chamada de "Sequência Observada", onde os quadros foram colocados na ordem de leitura da sequência criada por cada participante, os quadros ignorados estão destacados e no final está a justificativa do entrevistado para a sua escolha; a segunda parte alterada para "Discurso-Participante", contém o perfil do participante (idade e formação acadêmica) e a transcrição da história criada, destacando os elementos da narrativa citados na ficha base. Assim foi possível fazer um paralelo entre a sequência e o discurso originais e aqueles criados pelos participantes.

\subsection{Resultados}

Em relação a sequência de leitura, 8 dos participantes decidiram passar por todos os quadros seguindo o sentido horizontal, da esquerda para direita, justificando que estão geralmente acostumados a realizar a leitura de quadrinhos assim, e que mesmo não possuindo informações textuais (legendas) decidiram seguir a leitura como estavam habituados a realizar em artefatos deste tipo. Apenas 2 participantes, Po5 (Figura 13) e Po8 (Figura 14), realizaram sentido de leitura diferentes. 
Figura 13 e 14 Fichas de análise das narrativas dos participantes Po5 e P08 que apresentaram visões diferenciadas na escolha da sequência de leitura da ilustração Fonte: Elaborado pelos autores, com base na pesquisa realizada.
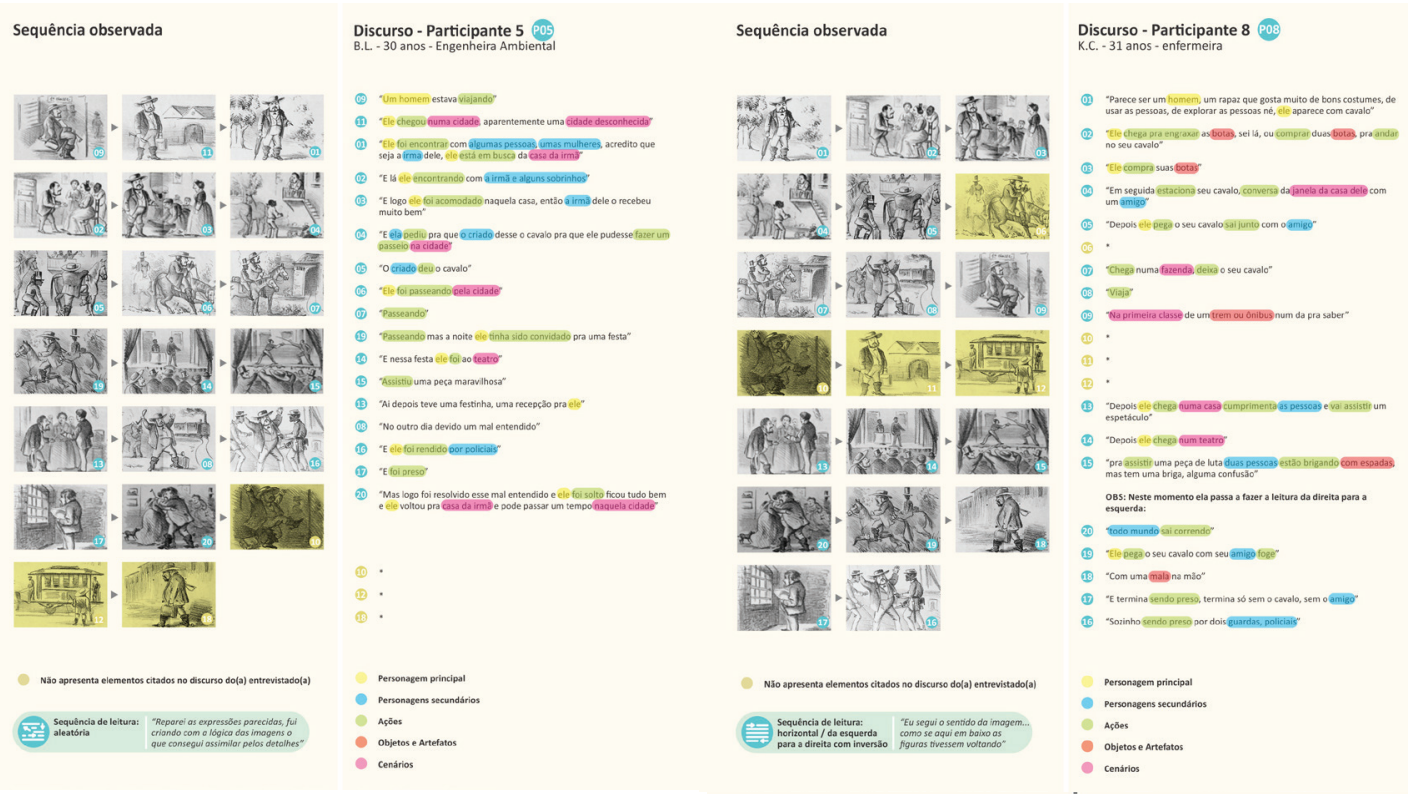

A "participante P05 - B.L.", decidiu por uma leitura totalmente aleatória, ou seja, misturou todos os quadros e justificou que tentou fazer ligações entre os detalhes de cada desenho ao criar uma ordem própria. A "participante Po8 - K.C.”, iniciou a leitura como a maioria no sentido horizontal, da esquerda para a direita, entretanto na última linha, inverteu o sentido seguindo da direita para a esquerda, sua justificativa está ligada a observação já realizada na descrição da ilustração no item 2.2, onde nos últimos 4 quadros da ilustração o Senhor Pancracio é desenhado neste sentido, ou seja, a participante seguiu o sentido do personagem para finalizar sua história. É interessante ressaltar ainda que quando lhes foi entregue a ilustração com o texto-legenda ambas seguiram o sentido original, sem qualquer hesitação, pois a legenda passou a guiar seu sentido de leitura.

A partir da interpretação dos discursos e da marcação das categorias: Personagem Principal, Personagens Secundários, Ações, Objetos e Artefatos e Cenários, foi elaborada a tabela a seguir (Tabela 1), onde é possível verificar e quantificar as categorias que foram encontradas nos discursos de cada entrevistado em comparação com as categorias existentes no discurso original, quadro a quadro: 
Oliveira Í. S. C. S., Silva F. B., Miranda E. R., Coutinho S. G. \& Leite H. L. A. | Análise de histórias produzidas a partir da observação da ilustração sequencial "infaustas aventuras do Senhor Pancracio"

Tabela 1 Categorias encontradas nos discursos.

Fonte: Elaborado pelos autores, com base na pesquisa realizada.

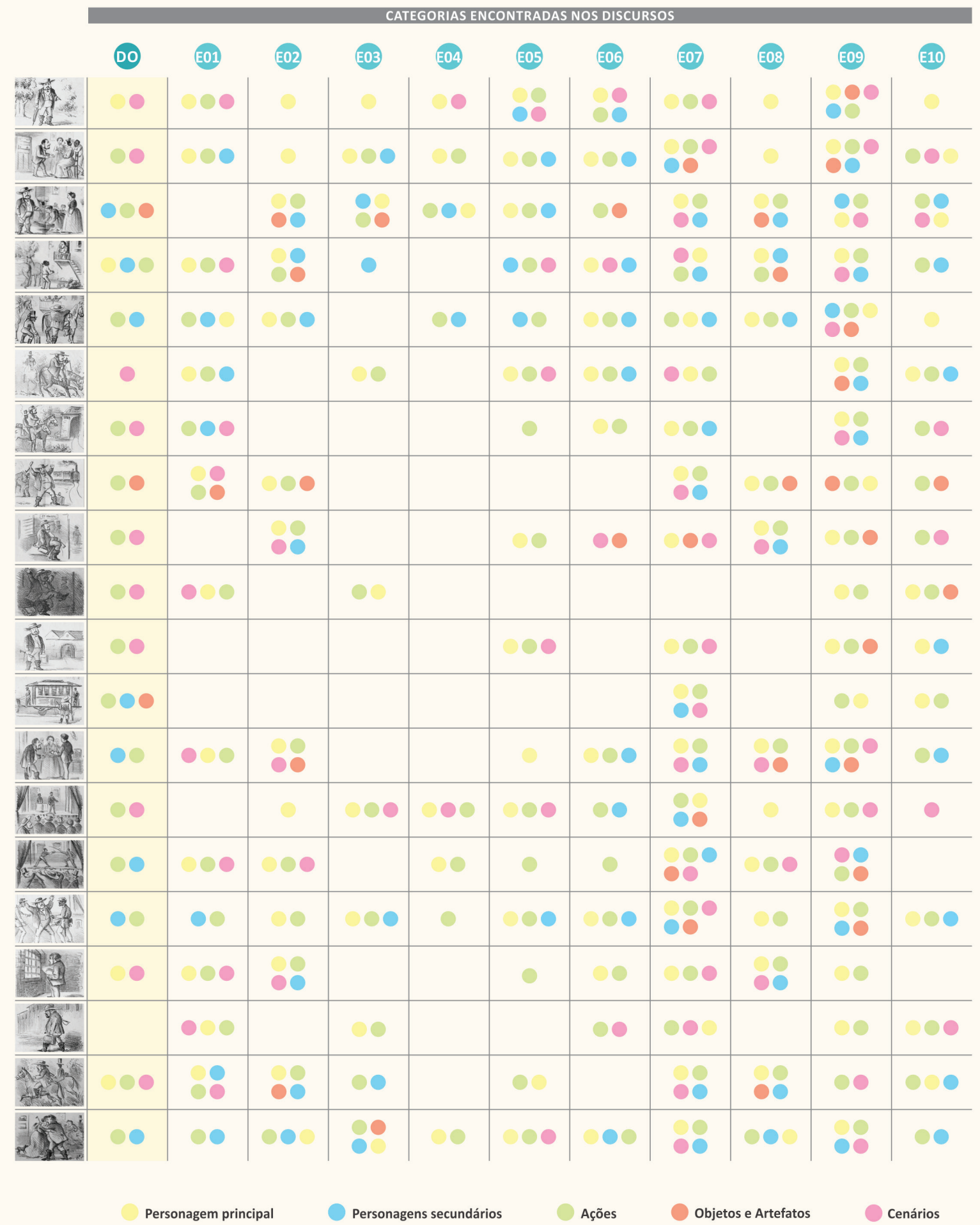

Foi possível observar também após a organização da tabela que os quadros 10, 11 e 12 que apresentam a sequência em que o Senhor Pancracio atravessa o túnel, chega a Estação das Cinco Pontas, e 
tenta pegar o bonde, foram aqueles que apresentaram menos possibilidades de interpretação sendo, portanto, os mais ignorados. Ficou nítido que quando o participante não compreendia o quadro, ele automaticamente passava para o posterior e não incluía nenhum tipo de referência daquele quadro em sua história.

No tocante a temporalidade da ilustração todos os participantes relataram que se tratava de uma temática antiga, surgiram dúvidas apenas entre os participantes P02, Po5 e Po9, referentes a temporalidade do traço do artista, este questionamento foi solucionado quando os mesmos visualizaram a ilustração o com o texto-legenda, pois a caligrafia e a ortografia diferentes das atuais lhes auxiliou na compreensão de que se tratava de uma ilustração do século XIX. Os elementos que com o olhar contemporâneo dos entrevistados foram citados como referência a uma temática temporal antiga, podem ser visualizados no gráfico a seguir (Gráfico 1) onde as colunas representam a quantidade de opiniões expressas para cada elemento destacado:

Gráfico 1 Opiniões expressadas durante as entrevistas.

Fonte: Elaborado pelos autores, com base na pesquisa realizada.

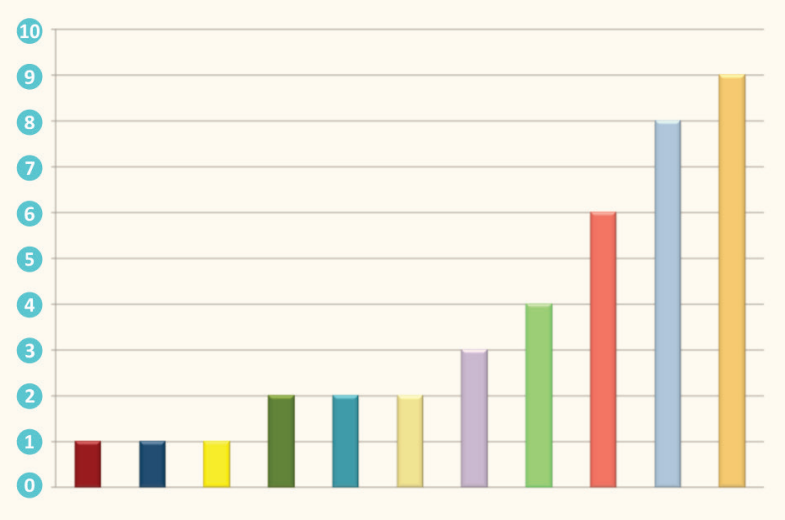

Ausência de cor

Falta de bordas ou linhas nos quadros

Traço rabiscado e proporção do personagem

Teatro e a peça

Construções, arquitetura das casas

Armas (espadas)

Escravo

Carruagem, Charrete, Carroça (bonde)

Trem a vapor

Cavalos

Vestimentas

A respeito da legenda e sua relação com o texto podemos destacar 4 variações de opiniões a seguir:

- 9 participantes - Apesar de conseguir criar uma história, ajudou a esclarecer detalhes que não foram compreendidos.

- 3 participantes - Ajudou a definir se o desenho é antigo ou recente pela ortografia e caligrafia.

- 2 participantes - Ajudou a esclarecer a ordem da sequência de leitura: horizontal, da esquerda para direita.

- 1 participante - Ajudou a entender a passagem do tempo (Dia/ noite - legenda do $14^{\circ}$ quadro: "a noite vae ao theatro"). 


\section{CONCLUSÃO}

Verificou-se que uma ilustração do final do século XIX, com elementos que remetiam a uma temática considerada antiga para a maioria dos participantes, mesmo sendo restrita do seu contexto histórico e informações textuais (texto-legenda), resultou em uma pluralidade de histórias que apesar de possuir algumas particularidades e detalhes diversificados (que foram observados nos discursos), resultaram no geral em histórias com um enredo semelhante e próximo do original, pois todos visualizaram um senhor que fez algum tipo de viagem, na qual ocorreram sustos, insatisfações, algumas confusões que fazem com que o mesmo seja preso e acabe decidindo voltar pra casa.

Assim foi possível constatar que os participantes conseguiram construir uma sequência de leitura da ilustração e até mesmo aqueles (Po5 e Po8) que criaram sequências aleatórias tiveram como resultado histórias semelhantes aos demais. Deve-se ressaltar ainda que foi possível observar que a multiplicidade nos detalhes das interpretações nas narrativas esta associado ao repertório pessoal do participante, ou seja, suas experiências e senso comum de alguma forma refletiram e influenciaram na criação das mesmas.

Além da semelhança entre os enredos desenvolvidos no exemplo estudado, pode ser percebida que a referência da maioria dos participantes para escolha da sequência de leitura da "esquerda para a direita em linhas", recebeu influência das histórias em quadrinhos, que mesmo nos dias atuais, perpetua o mesmo sentido de leitura da ilustração abordada. McCloud (1994), usa a seguinte expressão "os quadrinhos de hoje dançam com o invisível melhor do que antigamente" para abordar a legítima evolução da ilustração sequencial, entretanto mesmo havendo algumas inovações na diagramação das páginas das histórias em quadrinhos da atualidade, a maneira como é realizada a sequência de leitura, permanece bastante semelhante à da ilustração do século XIX apresentada nesta pesquisa, ambas influenciadas pela escrita ocidental.

\section{REFERÊNCIAS}

BARRETO CAMPELLO, Silvio; ARAGÃO, Isabella. Imagens comerciais de Pernambuco: ensaios sobre os efêmeros da Guaianases. Recife: Néctar, 2011.

CAVALCANTI, Laílson de Holanda. Humor Diário: a ilustração humorística do Diário de Pernambuco (1914-1996). Recife: Editora Universitária da UFPE, 1996.

EISENBERG, Peter L. Modernização sem mudança: a indústria açucareira em Pernambuco: 1840/1910. Rio de Janeiro: Paz e Terra, 1977. 
JACOBSON, Robert. Information design. Cambridge (MA): The MIT Press.p. 8-9, 2000.

MCCLOUD, Scott. Understanding Comics The Invisible Art. Harper Paperbacks: New York, 1994.

MEGGS, Philip B. História do Design Gráfico. São Paulo: Cosac Naify, 2009.

MELO, Chico Homem de; RAMOS, Elaine. Linha do Tempo do Design Gráfico no Brasil. São Paulo: Cosac Naify, 2011.

PEETERS, Benoît. Case, planche et récit: comment lire une bande déssinée Tournai. Casterman, 1991.

REZENDE, Antonio Paulo. (Des)encantos modernos: histórias da cidade do Recife na década de XX. Recife: FUNDARPE, 1997.

SPINILLO, Carla Galvão. An analytical approach to procedural pictorial sequences. Tese (Doutorado em Tipografia e Comunicação Gráfica) Department of Typography \& Graphic Communication, The University of Reading, 2000.

\title{
Sobre os autores
}

\author{
Íkaro Santhiago Câmara Silva Oliveira \\ ikarocamara@gmail.com \\ Universidade Federal de Pernambuco \\ Centro de Artes e Comunicação \\ Departamento de Design \\ Programa de Pós-graduação em Design
}

\section{Flávio Barbosa da Silva}

flavio.pontual@hotmail.com

Universidade Federal de Pernambuco

Centro de Artes e Comunicação

Departamento de Design

Programa de Pós-graduação em Design

\author{
Eva Rolim Miranda \\ evarolim@gmail.com \\ Universidade Federal de Pernambuco \\ Centro de Artes e Comunicação \\ Departamento de Design \\ Programa de Pós-graduação em Design
}

\section{Solange Galvão Coutinho}

solangecoutinho@globo.com

Universidade Federal de Pernambuco

Centro de Artes e Comunicação 
Departamento de Design

Programa de Pós-graduação em Design

Hana Luzia de Abreu Leite

hanaluzia@gmail.com

Universidade Federal de Pernambuco

Centro de Artes e Comunicação

Departamento de Design

Programa de Pós-graduação em Design

Edição especial P\&D2016

Artigo recebido em 23/09/2016

Artigo aceito em 30/09/2016 